\title{
Cognitive behavioral therapy for the treatment of post-traumatic stress disorder: a review
}

\author{
This article was published in the following Dove Press journal: \\ Neuropsychiatric Disease and Treatment \\ | April 201 I \\ Number of times this article has been viewed
}

\section{Nilamadhab Kar \\ Department of Psychiatry, Wolverhampton City Primary Care Trust, Wolverhampton, UK}

Correspondence: Nilamadhab Kar Corner House Resource Centre, 300 Dunstall Road, Wolverhampton, WV6 ONZ, UK

Tel +44 1902553798

Fax +441902553383

Email nmadhab@yahoo.com
Background: Post-traumatic stress disorder (PTSD) is a psychiatric sequel to a stressful event or situation of an exceptionally threatening or catastrophic nature. Cognitive behavioral therapy (CBT) has been used in the management of PTSD for many years. This paper reviews the effectiveness of CBT for the treatment of PTSD following various types of trauma, its potential to prevent PTSD, methods used in CBT, and reflects on the mechanisms of action of CBT in PTSD.

Methods: Electronic databases, including PubMed, were searched for articles on CBT and PTSD. Manual searches were conducted for cross-references in the relevant journal sites.

Results: The current literature reveals robust evidence that CBT is a safe and effective intervention for both acute and chronic PTSD following a range of traumatic experiences in adults, children, and adolescents. However, nonresponse to CBT by PTSD can be as high as 50\%, contributed to by various factors, including comorbidity and the nature of the study population. CBT has been validated and used across many cultures, and has been used successfully by community therapists following brief training in individual and group settings. There has been effective use of Internet-based CBT in PTSD. CBT has been found to have a preventive role in some studies, but evidence for definitive recommendations is inadequate. The effect of CBT has been mediated mostly by the change in maladaptive cognitive distortions associated with PTSD. Many studies also report physiological, functional neuroimaging, and electroencephalographic changes correlating with response to CBT.

Conclusion: There is scope for further research on implementation of CBT following major disasters, its preventive potential following various traumas, and the neuropsychological mechanisms of action.

Keywords: post-traumatic stress disorder, cognitive behavioral therapy, prevention, treatment, mechanisms of action, trauma

\section{Introduction}

Post-traumatic stress disorder (PTSD) is a debilitating mental health condition frequently associated with psychiatric comorbidity and diminished quality of life, and typically follows a chronic, often lifelong, course. ${ }^{1}$ Given the ubiquitous nature of threatening or catastrophic trauma, PTSD is becoming more and more common. It may affect $10 \%$ of women and $5 \%$ of men at some stage. ${ }^{2}$ Depending upon the nature and degree of the traumatic event, the prevalence rates of PTSD in victims have been reported to approach $100 \%{ }^{3}$ The PTSD syndrome is a conglomeration of various cognitive, behavioral, and physiological disturbances characterized by three symptom clusters, ie, intrusion, avoidance, and arousal. 
Since the introduction of PTSD into the diagnostic classificatory systems in $1980,{ }^{4}$ considerable research has been done on the efficacy of cognitive behavioral therapy (CBT) in its treatment. ${ }^{5}$ Currently, trauma-focused CBT is recommended for PTSD by various treatment guidelines and expert consensus panels. ${ }^{6-10}$ The purpose of this review is to evaluate the studies of CBT for PTSD following various types of trauma, and those related to physical disorders in adults, children, and adolescents. It is also intended to review the long-term outcome and preventive role of CBT in PTSD and various modes of delivery of CBT in practice, and the current understanding of its mechanism of action is also discussed.

\section{Methods}

A literature search was conducted in electronic databases, including PubMed, for articles on CBT and PTSD. Search with key terms of ("cognitive behavior therapy" OR CBT[All Fields]) AND ("stress disorders, posttraumatic" [MeSH Terms] OR ("stress" [All Fields] AND "disorders" [All Fields] AND "post-traumatic" [All Fields]) OR "post-traumatic stress disorders" [All Fields] OR "PTSD" [All Fields]) resulted in 192 articles representing 58 randomized controlled trials. A further manual search found seven further randomized controlled trials in the relevant area. Studies that did not include patients with PTSD or CBT, or were not relevant to the topic, were excluded. This left 31 randomized controlled trials involving CBT in PTSD patients (see Table 1). ${ }^{11-41}$ In addition, manual searches were conducted for relevant articles in specific areas for a comprehensive review. While the randomized controlled trials have established the efficacy of CBT in PTSD secondary to various types of trauma in different situations and age groups, various other studies have widened the applicability and usability of CBT in PTSD. There is extensive literature in this area which needs comprehensive review.

\section{CBT for PTSD in adults}

\section{Terrorism}

CBT has been found to be effective for PTSD following terrorist attacks, eg, in the survivors of the 9/11 terrorist attack on the World Trade Center, ${ }^{42}$ the 2005 London bombings, ${ }^{43}$ and the 1998 bomb explosion in Omagh, Northern Ireland. ${ }^{44}$ CBT for the victims of the World Trade Center attack was manualized, applied flexibly, in 12-25 sessions, by therapists with no prior training through to extensive training in CBT. There were significant pre-post reductions in symptoms of PTSD and depression. ${ }^{42}$ The improvement in PTSD in victims of the 2005 London bombings was well maintained at an average of one year later. ${ }^{43}$ Patients with PTSD secondary to the bomb explosion in Omagh received an average of eight treatment sessions by staff with modest prior training in CBT for PTSD. However, the degree of improvement was comparable with that in reported research trials, in spite of the fact that almost half of the patients $(53 \%)$ had psychiatric comorbidity. ${ }^{44}$

\section{War trauma}

The traumas of war have long been associated with PTSD. In addition, soldiers exposed to combat remain at high risk for developing the disorder. ${ }^{45}$ Multicomponent CBT showed promise in a group of male combat veterans with severe and chronic PTSD for improving social functioning beyond that provided by exposure therapy alone, particularly by increasing social engagement and interpersonal functioning. ${ }^{46} \mathrm{CBT}$ with brief virtual reality exposure has been found to be beneficial in treating PTSD in war veterans. ${ }^{45} \mathrm{~A}$ 12-session integrated treatment using components of cognitive processing therapy for PTSD, and CBT for chronic pain management in veterans with comorbid chronic pain and PTSD, suggested not only the feasibility of this treatment approach but also clinical benefit. ${ }^{47}$

\section{Sexual assault}

There is evidence that CBT is successful in reducing the symptoms of PTSD following assault on females, rape, ${ }^{32,48,49}$ and childhood sexual abuse. ${ }^{33}$ It has been observed that these gains could be maintained in the long term at follow-up assessments. ${ }^{32,48}$ A study comparing prolonged exposure alone, prolonged exposure plus cognitive restructuring, or wait-list in female patients with chronic PTSD following sexual assault, found that both treatments reduced PTSD and depression in intent-to-treat (ITT) and completer samples compared with wait-list. However, the addition of cognitive restructuring did not enhance the treatment outcome. This study showed that treatment by counselors with minimal CBT experience was as efficacious as that of CBT experts. ${ }^{50}$ Studies have found that CBT helps to decrease self-reported PTSD severity and associated anxiety, and that participants do not meet criteria for a PTSD diagnosis at follow-up assessments, showing sustained improvement. ${ }^{32,33}$

\section{Road traffic accidents}

Motor vehicle accidents are common precipitants of PTSD. There is evidence for efficacy of trauma-focused CBT for motor vehicle accident-related PTSD. ${ }^{18,51} \mathrm{CBT}$ elements, like 


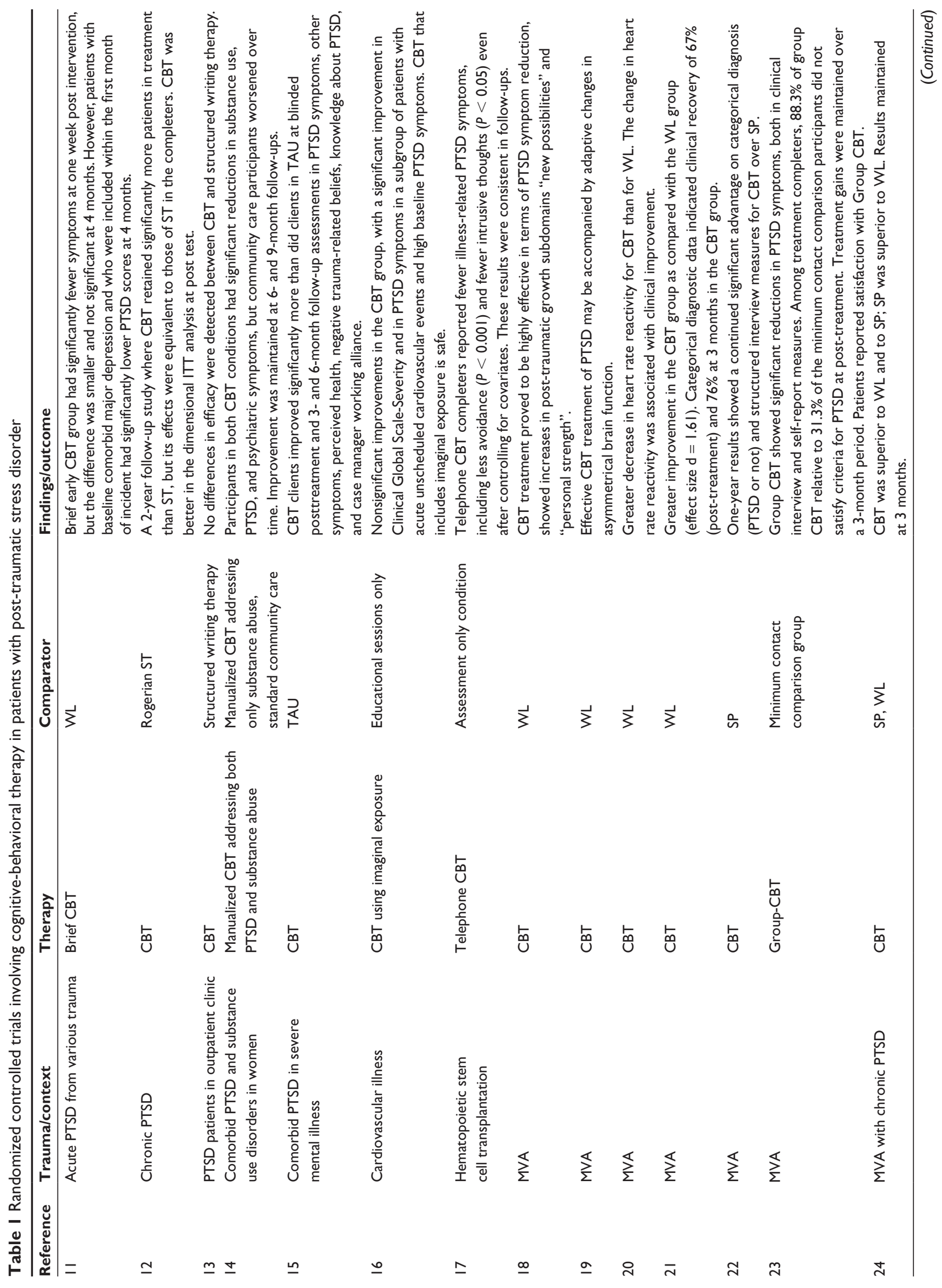




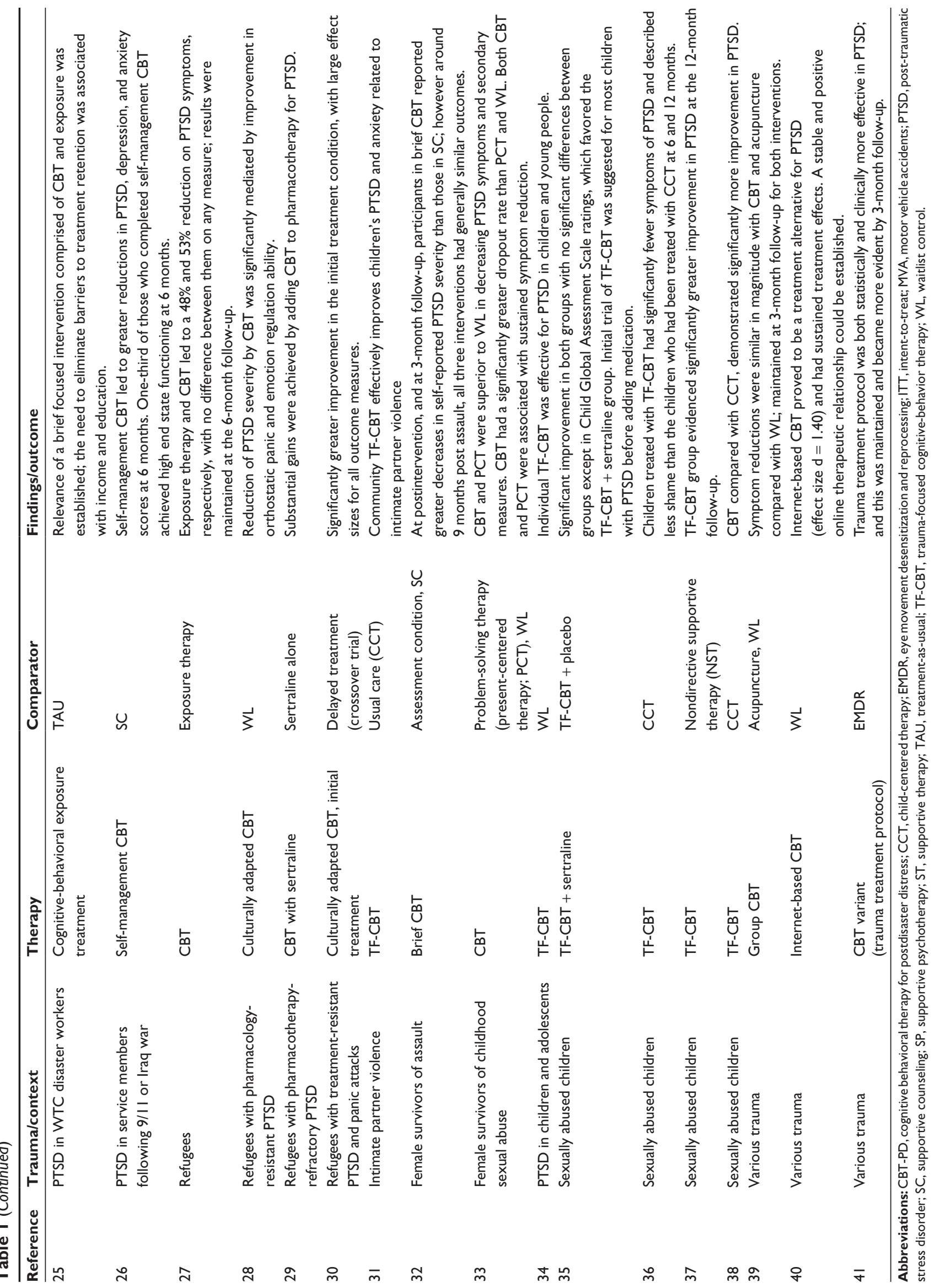


imaginal reliving and facilitating of post-traumatic growth, have been used in motor vehicle accident survivors with full or subsyndromal PTSD, which has led to significant improvement that has been stable at follow-up. ${ }^{21}$ Group CBT has also been studied for PTSD following a serious motor vehicle accident, with special considerations for strategies to reduce the potential for triggering re-experiencing of symptoms during group sessions. The results suggested that group CBT is an effective treatment for motor vehicle accident-related PTSD. ${ }^{52}$ However, inadequate response to CBT has been reported in a proportion of cases. A 12-week course of CBT for people with motor vehicle accident-related PTSD reported a partial response in $40 \%$ of cases. Compared with responders, partial responders tended to have more severe pretreatment numbing symptoms and greater anger about their accident, along with lower global levels of functioning, greater pain severity and interference, and greater depression, and were more likely to be taking psychotropic medications. ${ }^{53}$

\section{Refugee status}

Refugees with PTSD often present with complicated traumatic symptoms, prolonged and repeated exposure to traumatic events, acculturation, and social problems. There are many studies of CBT in refugees, suggesting its effectiveness. ${ }^{27}$ Therapy issues, like adapting the CBT to the culture and language of the refugees, are challenging and have been addressed in some studies. ${ }^{29} \mathrm{~A}$ program of CBT emphasizing information, exposure, and cognitiverestructuring has been successfully used in refugees. ${ }^{29}$ Large effect sizes have been obtained in some of the CBT studies, indicating a broad suitability of CBT in this area. ${ }^{54}$ Refugees with pharmacology-resistant PTSD have also benefitted from CBT. ${ }^{28}$ In a sample of Vietnamese refugees with treatment-resistant PTSD and panic attacks, CBT indicated significant improvements for all outcome measures, ie, the Harvard Trauma Questionnaire, Anxiety Sensitivity Index, Hopkins Symptom Checklist-25 (HSCL-25)-anxiety subscale, and Hopkins Symptom Checklist-25-depression subscale scores. ${ }^{55}$ In an illustrative case report, a tortured male asylum-seeker living in Sweden who received 16 sessions of CBT, involving mainly self-exposure to trauma-related cues, had significant improvement across all measures of PTSD, anxiety, and depression, which was maintained at six-month follow-up. ${ }^{56}$ However, effectiveness of CBT treatments has not as yet been tested on the whole range of symptoms in refugees with maladaptive traumatic reactions that can take the shape of more complex reactions.

\section{Disaster workers}

Disaster workers are exposed to shocking scenes and humanitarian suffering, and are particularly vulnerable to developing stress symptoms, including PTSD, in spite of their training and preparedness for disaster work. In fact, high rates of PTSD in disaster workers have been reported worldwide. Studies of CBT in this area are scarce, but there is evidence of support for the relevance of a brief focused intervention comprising CBT for disaster workers. ${ }^{25}$

\section{Disorders associated with PTSD Insomnia}

Insomnia is one of the most common symptoms of PTSD and often persists after other symptoms have responded to CBT. In a study of patients who no longer met the criteria for a PTSD diagnosis following CBT for PTSD, 48\% reported residual insomnia. However, for the large majority, insomnia persisted in the absence of continuing nightmares and hypervigilance. Experiencing trauma in a sleeprelated context was associated with greater risk for residual insomnia. ${ }^{57}$ The response of insomnia to CBT treatment has been specifically addressed in some studies. The outcome of five sessions of cognitive-behavioral treatment for insomniac patients who responded to CBT for PTSD, but continued to report insomnia, suggested improvements on subjective sleep measures and self-monitored sleep efficiency in most cases.$^{58}$ In one study, rape victims with PTSD who responded to CBT also had significantly decreased sleep disturbance following therapy. ${ }^{49}$

\section{Physical conditions}

Serious physical conditions and events are linked to development of PTSD. Many studies have tried to evaluate the effectiveness of CBT in these conditions, ranging from malignancy, cardiovascular disorders, physical trauma, brain injuries, and postnatal PTSD. ${ }^{16,17}$ The physical safety of CBT utilizing imaginal exposure in patients who suffer PTSD following a life-threatening cardiovascular event has been established. ${ }^{16}$ In a study of myocardial infarction survivors with PTSD, it was found that PTSD symptoms and cardiovascular risk improved in patients who received CBT. PTSD was found to be a treatable risk factor for poor post-myocardial infarction outcome. ${ }^{59} \mathrm{CBT}$ has also been suggested to be the treatment of choice in PTSD secondary to intraoperative awareness with subsequent recall. ${ }^{60}$ Approximately $1 \%-2 \%$ of women suffer from postnatal PTSD, with wide-ranging consequences for themselves and their families. CBT has been reported to be effective in postnatal PTSD. ${ }^{61}$ However, there 
is limited evidence concerning the management of women with PTSD after childbirth. CBT may improve PTSD in this setting, but controlled trials are needed before conclusions can be drawn. ${ }^{62}$

Injured trauma survivors are a known risk group for PTSD, and given the complex circumstances and comorbidities of this population, it is expected that PTSD might impact treatment delivery and outcome. The suitability of CBT for the treatment of injured trauma survivors with PTSD has been suggested, with special consideration of treatment delivery within the trauma care system. ${ }^{63}$ There are examples of use of CBT for managing PTSD symptoms in patients with traumatic brain injury, which include use of a stress inoculation and graduated exposure to avoided situations and trauma reexperiences. Set within a neurorehabilitation program, CBT has led to improvement in PTSD symptoms and psychosocial outcome in traumatic brain injury survivors. ${ }^{64}$

\section{Studies involving other types of trauma}

There are examples of use of CBT following natural disasters affecting huge populations. ${ }^{65-68}$ It has been proposed that a randomized controlled trial of CBT for PTSD must be conducted with public health relevance and enhanced methodological rigor. ${ }^{69}$ Systematic reviews have found that individual and group trauma-focused CBT is effective in the treatment of PTSD following various kinds of trauma. ${ }^{70}$ Psychological treatments empirically supported for PTSD following different kinds of trauma are trauma-focused CBT and eye movement desensitization and reprocessing (EMDR), which are efficacious and specific for PTSD. ${ }^{51}$

\section{CBT for PTSD in children and adolescents}

PTSD is a common psychiatric condition in childhood and adolescence following traumatic events. ${ }^{71,72} \mathrm{CBT}$ has been considered to be the first choice of treatment of PTSD in children and adolescents. ${ }^{73,74}$ The effectiveness and feasibility of CBT have been established even for preschool children with PTSD following a range of traumatic events. It has been concluded that young children can cooperate meaningfully in structured, trauma-related exposure exercises and can utilize relaxation techniques successfully. Highly anxious parents do not inhibit their children's improvement per se, as long as they can facilitate the manual techniques. ${ }^{75}$ Studies of CBT in children comparing PTSD with EMDR and play therapy are methodologically more rigorous, having used manualized, reproducible treatment, and contain examples of group-based or school-based therapies. ${ }^{76}$
In a randomized controlled trial, children and young people with PTSD who received individual trauma-focused CBT experienced significantly greater improvement in symptoms not only of PTSD, but also depression and anxiety, with significantly better functioning compared with wait-list. While $92 \%$ of participants no longer met criteria for PTSD after CBT, this figure was $42 \%$ in the wait-list group. CBT gains were maintained at six-month follow-up. ${ }^{34}$ An 18-week, group-administered course of CBT for pediatric PTSD after a single-incident stressor reported that the majority of patients (82.4\%) completed treatment. Of these, 57\% no longer met the criteria for PTSD immediately after treatment, and $86 \%$ were free of PTSD at six-month follow-up. CBT produced a robust beneficial effect after treatment on the ClinicianAdministered PTSD Scale-Child and Adolescent Version, with additional improvement accruing at follow-up on ITT analyses. ${ }^{77}$

\section{Natural disasters}

The efficacy of CBT in alleviating symptoms of PTSD after catastrophic disaster has been demonstrated in children and adolescents. ${ }^{66,78}$ Following the 1999 earthquake in Athens, short-term CBT in a group of children who were experiencing PTSD symptoms revealed a significant reduction in overall symptoms across intrusion, avoidance, and arousal symptom clusters, as well as in depressive symptoms immediately after the intervention. The therapy also produced a significant improvement in children's psychosocial functioning. Further significant improvement was reported at 18-month follow-up, which was maintained at four-year follow-up. This study suggested that short-term group CBT can be offered in clinical settings, particularly if resources are limited. ${ }^{79} \mathrm{CBT}$ for adolescents exposed to the 2004 earthquake in Bam, Iran, led to a significant decrease in severity of PTSD symptoms in each of three symptom categories (intrusion, avoidance, and arousal) and in the total score for PTSD. ${ }^{66}$

\section{Man-made traumas}

A growing number of studies of child abuse victims have supported the effectiveness of trauma-focused CBT. ${ }^{80} \mathrm{~A}$ review article found that promising treatments for war-related PTSD in refugee children and adolescents include CBT, testimonial psychotherapy, narrative exposure therapy, and EMDR. ${ }^{81}$ A school mental health program consisting of manualbased, eight-session, group CBT delivered by bilingual, bicultural school social workers, supported Latino immigrant students who had been exposed to community violence. 
The outcome was a modest decline in trauma-related mental health problems. This study demonstrated that programs for traumatized youth can be designed for delivery on school campuses by school clinicians, and can be implemented and evaluated in the school setting. ${ }^{82}$ In a study of Palestinian adolescent victims of armed conflict, it was suggested that trauma-focused CBT addressing negative coping and fatalism may yield positive results. ${ }^{83}$ More research is needed to determine the critical components and optimal administration of CBT and to evaluate the efficacy of this approach for other groups of child crime victims.

\section{Sexual abuse}

There is growing evidence supporting the effectiveness of trauma-focused CBT in children suffering PTSD as a result of sexual abuse..$^{36,38}$ Trauma-focused CBT for symptomatic children has been successful within 1-6 months of experiencing sexual abuse. Several controlled and open-label studies of traumatized children with chronic PTSD have provided additional support for trauma-focused CBT interventions. However, the optimal dosage and critical components of trauma-focused CBT have not been determined ${ }^{84} \mathrm{~A}$ family-wide CBT framework for sexually abused children with PTSD that involves both child and nonoffending caregivers has been found to be supportive. ${ }^{85}$ Compared with child-centered therapy, trauma-focused CBT has demonstrated significantly more improvement with regard to PTSD, depression, behavior problems, shame, and abuse-related attributions in sexually abused children. Similarly, parents/caregivers who receive trauma-focused CBT show greater improvement with respect to their own self-reported levels of depression, abuse-specific distress, support of the child, and effective parenting practices. ${ }^{36,38}$

\section{CBT for PTSD as a comorbid psychiatric condition}

PTSD is often observed as a comorbidity of other psychiatric disorders, most commonly depressive or anxiety disorders. Comorbidity of PTSD impacts upon the outcome unless it is identified and addressed. In acute PTSD patients with baseline comorbid major depression, brief early CBT has been observed to lower PTSD scores significantly, both at one week and at four months. ${ }^{11}$ A study comprising PTSD patients with comorbidity of major mood disorder $(85 \%)$ or schizophrenia or schizoaffective disorder $(15 \%)$, of whom $25 \%$ also had borderline personality disorder, reported a CBT participation rate of $81 \%$. CBT patients improved significantly more than did patients on treatment as usual at blinded post-treatment and three-month and six-month follow-up assessments of PTSD symptoms, negative trauma-related beliefs, perceived health, and knowledge about PTSD. The findings suggest that clients with severe mental illness and PTSD can benefit from CBT, despite severe symptoms, suicidal thinking, psychosis, and vulnerability to hospitalization. ${ }^{15}$ Co-occurring PTSD is a known risk factor for negative outcomes in the treatment for substance use disorders. However, a favorable response has been reported for substance use, PTSD severity and retention in patients who received CBT for comorbid PTSD provided by community therapists in this patient group. ${ }^{86}$

\section{Comparisons with other psychotherapies}

Various forms of therapies have been compared with CBT in the treatment of PTSD, namely supportive psychotherapy, problem-solving therapy, present-centered therapy, psychodynamic therapy, hypnotherapy, acupuncture, and structured writing therapy. ${ }^{12,13,39}$ However, more consistent comparison has been with EMDR. A systematic review of 23 clinical trials on the efficacy of CBT in comparison with other psychotherapies suggested that CBT had better remission rates than EMDR or supportive therapies. CBT was comparable with exposure therapy and cognitive therapy in terms of efficacy and compliance. These findings suggested that specific therapies, such as CBT, exposure therapy, and cognitive therapy are equally effective, and more effective than supportive techniques in the treatment of PTSD. ${ }^{87}$ Another systematic review of 33 randomized controlled trials compared all psychological treatments for adults suffering from traumatic stress symptoms for three months or more. Types of interventions studied were trauma-focused CBT/exposure therapy, stress management, other therapies (supportive therapy, nondirective counseling, psychodynamic therapy, and hypnotherapy), group CBT, and EMDR. With regard to reduction of clinician-assessed PTSD symptoms measured immediately after treatment, trauma-focused CBT did significantly better than other therapies and wait-list/usual care. There is no significant difference between trauma-focused CBT and stress management, trauma-focused CBT, and EMDR. Group trauma-focused CBT was significantly better than wait-list/usual care. It was concluded that individual and group trauma-focused CBT, EMDR, and stress management are effective in the treatment of PTSD. There was some evidence that individual trauma-focused CBT and EMDR are superior to stress management in the treatment of PTSD at 2-5 months following treatment. ${ }^{70}$ 


\section{Eye movement desensitization and reprocessing}

EMDR and trauma-focused CBT are both widely used in the treatment of PTSD and have been consistently compared. While most studies find them better than other therapies, and equally efficacious; there are studies which suggest superiority of CBT over EMDR. ${ }^{41}$ A systematic review of 38 randomized controlled trials reported that trauma-focused CBT, EMDR, stress management, and group CBT improved PTSD symptoms more than wait-list or usual care. There was inconclusive evidence regarding other therapies. There was no evidence of a difference in efficacy between traumafocused CBT and EMDR, but there was some evidence that trauma-focused CBT and EMDR were superior to stress management and other therapies. The results suggested that the first-line psychological treatment for PTSD should be trauma-focused CBT or EMDR ${ }^{88}$ A meta-analysis of seven studies suggested that trauma-focused CBT and EMDR tend to be equally efficacious, and superiority of one treatment over the other could not be demonstrated. ${ }^{89}$

\section{Nonresponse to CBT}

Nonresponse and dropouts are common in CBT for PTSD, and many patients fail to attain remission with it. ${ }^{90} \mathrm{~A}$ review of 55 studies found that the nonresponse rates could be as high as 50\%. ${ }^{91,92}$ Dropout rates ranged widely, and may have depended, at least in part, on the nature of the study population. ${ }^{91}$ It is essential to discuss the potential factors associated with nonresponse. In a clinical setting, the completion rate for CBT has been observed to be markedly lower than rates reported in randomized trials. CBT completion was inversely related to severity of overall pretreatment measures of PTSD, avoidance, hyperarousal, depression, impaired social functioning, and borderline personality disorder. In one particular study, initiating imaginal exposure therapy was associated with greater likelihood of completion. ${ }^{93}$ The dropout of disaster workers after the World Trade Center attack was associated with lower income, less education, and higher alcohol consumption. There is a need to eliminate barriers to treatment retention. ${ }^{25}$ Partial response in cases of motor vehicle accident-related PTSD was associated with more severe pretreatment numbing, greater anger regarding motor vehicle accident, lower global level of functioning, greater pain severity, and greater depression. ${ }^{53}$

\section{CBT and long-term outcome}

There are many follow-up studies which have looked into the long-term effect of CBT in PTSD patients.
Continued significant advantage on categorical diagnosis (PTSD or not) and structured interview measures for CBT over supportive psychotherapy at one year has been reported. At two years, although there were continued differences favoring CBT over supportive psychotherapy, only the differences in the PTSD Checklist, Impact of Event Scale scores, and overall categorical diagnoses were significant. There was very modest improvement from end of treatment to the two-year follow-up. ${ }^{22}$ In another study, two years after six sessions of CBT, CBT combined with hypnosis, or supportive counseling, civilian trauma survivors with acute stress disorder who received CBT and CBT-hypnosis reported less re-experiencing and less avoidance symptoms than patients who received supportive counseling. In terms of treatment completers, $10 \%$ of CBT patients, $22 \%$ of CBT-hypnosis patients, and $63 \%$ of supportive counseling patients met PTSD criteria at two-year follow-up. Considering the ITT analyses, the corresponding figures were $36 \%, 46 \%$, and $67 \%$, respectively. ${ }^{94}$

A follow-up study of civilian trauma survivors with acute stress disorder reported that $8 \%$ of CBT patients and $25 \%$ of supportive counseling patients met criteria for PTSD four years after the therapy. Patients who received CBT reported less intense PTSD symptoms, and particularly less frequent and fewer avoidance symptoms, than patients who received supportive counseling. These findings suggest that early provision of CBT in the initial month after trauma has long-term benefits for people who are at risk of developing PTSD. ${ }^{95}$ However, in an assessment of the long-term outcome of a randomized controlled trial of CBT for anxiety disorders, it was observed that patients with PTSD fared particularly poorly. Treatment with CBT was associated with a better long-term outcome than non-CBT in terms of overall symptom severity but not with regard to diagnostic status. The positive effects of CBT in the original trial eroded over longer time periods. CBT was associated with slightly higher costs than non-CBT and slightly higher benefits. ${ }^{96}$

\section{CBT and prevention}

The prevention of long-term psychological distress following traumatic events is a major concern. It is already known that current evidence does not support psychological debriefing for prevention of PTSD. ${ }^{97,98}$ Acute stress disorder is considered as a precursor of chronic PTSD. In a comparative study, patients with acute stress disorder were given five sessions of either CBT or supportive counseling within two weeks of civilian trauma. Fewer patients in the CBT group than those in the supportive counseling group 
( $8 \%$ versus $83 \%$ ) met the criteria for PTSD following treatment. There were also fewer cases of PTSD in the CBT condition (17\%) than in the supportive counseling condition (67\%) six months following the trauma. There were greater statistically and clinically significant reductions in intrusive, avoidance, and depressive symptomatology among the patients receiving CBT than in those receiving supportive counseling. This study not only demonstrated successful treatment of acute stress disorder with CBT but also its efficacy in preventing chronic PTSD. ${ }^{99}$ However, in another study, a brief CBT program given in the first month after trauma was not superior to repeated assessment, but a course of CBT of up to 16 sessions given at 1-4 months after trauma was superior to self-help, repeated assessment, and no intervention. The reasons for this superior response include the way of working through traumatic memories and the impact of the interventions on patient interpretation of PTSD symptoms. ${ }^{100}$

There is evidence from a meta-analysis of five randomized controlled trials for the superior effectiveness of traumafocused CBT within three months of trauma compared with supportive counseling in preventing chronic PTSD in patients with an initial acute stress disorder diagnosis. However, considering the limitations, replications are necessary to assess generalizability. Evidence for the effectiveness of trauma-focused CBT in traumatized populations without an acute stress disorder diagnosis can be considered to be insufficient. ${ }^{101}$ Another study indicated that multiple-session trauma-focused CBT beginning within three months of a trauma appeared to be effective for individuals with traumatic stress symptoms, especially those who meet the threshold for a clinical diagnosis. ${ }^{102}$

It is known that military personnel, emergency responders, disaster workers, and others whose work environments include exposure to traumatic events are at risk of developing PTSD. Possible cognitive-behavioral mechanisms in trauma adaptation and prevention interventions for at-risk professionals have been proposed based on current findings for CBT and empirical research on post-traumatic stress. ${ }^{103}$ It appears that early trauma-focused CBT holds promise as a preventive intervention for people at risk of developing chronic PTSD. The population impact of a preventive intervention depends on two factors, ie, what proportion of the full population at risk receives the intervention and how large a reduction in risk occurs among those who receive it. In an illustrative study, CBT demonstrated a larger effect size (50\% PTSD prevention), but minimal reach $(27 / 10,000)$, while a stepped collaborative care trial demonstrated a smaller effect size
(7\% PTSD prevention) but greater reach $(1762 / 10,000)$. Modeling of the population impact suggested that a 9.5 -fold greater cumulative reduction in the incidence of PTSD would result from the dissemination of the collaborative care broad reach prevention strategy. ${ }^{104}$

However, it is suggested that, at present, multiple session interventions aimed at all individuals exposed to traumatic events should not be used. ${ }^{105} \mathrm{~A}$ review and meta-analysis suggested that no psychological intervention can be recommended for routine use following traumatic events for prevention of PTSD, and that multiple session (two or more sessions) interventions, like single session interventions, may have an adverse effect on some individuals. ${ }^{105}$

\section{Pharmacotherapy-CBT interface}

A systematic review has investigated whether or not the combination of psychological therapy and pharmacotherapy is a more efficacious treatment for PTSD than either of these interventions delivered separately. There was no strong evidence to show differences between the group receiving combined intervention compared with the group receiving psychological therapy or pharmacotherapy. ${ }^{106}$ However, it has been suggested that combining medication approaches with psychotherapies that promote extinction, such as CBT, may offer patients with PTSD a rapid and robust treatment with good durability of effect. ${ }^{107}$ In a similar vein, CBT seems to be a promising next-step strategy for patients with PTSD who did not remit with drug-based therapies. ${ }^{108}$ In a sample of pharmacotherapy-refractory Cambodian refugees, combination treatment with sertraline and CBT for treating PTSD indicated substantial gains. ${ }^{29}$ However, another study found only minimal evidence for a combination of trauma-focused CBT and sertraline, and suggested an initial trial should be undertaken, with evidence-based psychotherapy before adding medication. ${ }^{31}$ Key recommendations of Australian clinical practice guidelines for PTSD indicate that medication should not be used in preference to trauma-focused psychological therapy (CBT or EMDR). ${ }^{9}$

\section{Methodological issues using CBT Cultural issues}

CBT has been used across cultures successfully, but needs to be adapted according to cultural and local issues. ${ }^{29,109}$ In the context of natural disasters, as well as psychiatric disorders, CBT has been found to be effective in many countries. ${ }^{109}$ Culturally adapted CBT in Vietnamese and Cambodian refugees with PTSD has been feasible, acceptable, and effective. ${ }^{55}$ 


\section{Training}

Studies suggest that community therapists can be trained in CBT for postdisaster distress in relatively short time spans with ongoing support in a real-world setting. This is especially important in emergency disaster situations, when a number of nonexpert trauma therapists will need to deliver trauma services ${ }^{67}$ to large numbers of people. ${ }^{110}$ The effectiveness of disseminating CBT for postdisaster distress to community therapists was studied following Hurricane Katrina. Following two days of training in CBT for postdisaster distress, therapists showed significant improvement in their ratings of the importance of various elements of CBT, their knowledge and understanding of those elements, and their confidence that they could use them effectively. Immediately following training, $90 \%$ of therapists demonstrated excellent retention of CBT for postdisaster distress. ${ }^{67}$ CBT for postdisaster distress, comprising 10 sessions, provided by community therapists addressing a range of cognitive, emotional, and behavioral reactions to disaster in adult survivors of Hurricane Katrina has been reported to be effective. Participants who were assessed at various phases of treatment showed significant and large improvements. The overall pre-post effect size was 1.4 in ITT analyses, and the benefits were maintained at follow-up. ${ }^{68}$

\section{Components of CBT}

CBT in the context of PTSD usually entails education about common reactions to trauma, relaxation training, and identification and modification of cognitive distortions. However, many specific elements have been used. Some of these involve imaginal reliving of the trauma memory, imaginal exposure, in vivo exposure, facilitation of post-traumatic growth, ${ }^{21}$ stress inoculation, graduated exposure to avoided situations and trauma re-experiences, ${ }^{64}$ exposure to trauma reminders, cognitive restructuring, and rescripting/imagery rescripting. ${ }^{11,111}$ Cognitive behavior interventions in older children have included direct discussion of the trauma, desensitization and relaxation techniques, and cognitive reframing. Contingency reinforcement programs for problematic behaviors have been suggested to be useful.

\section{Therapy settings}

CBT for PTSD has been provided in a variety of settings, including community centers, schools, primary care clinics, and hospitals at secondary and tertiary care levels, depending upon the context of the traumatic event or condition. For example, following natural disasters, CBT has been used in community centers and schools by community therapists, and the effectiveness of this method of CBT provision has been established. Considering the therapy sessions, CBT for PTSD is usually delivered in weekly or biweekly sessions. ${ }^{11}$ However, an intensive version of cognitive therapy for PTSD has recently been attempted. Patients received up to 18 hours of therapy over a period of 5-7 working days, followed by one session per week and up to three follow-up sessions. The results suggested that intensive cognitive therapy for PTSD was a feasible and promising alternative to weekly treatment. However, this warrants further evaluation in randomized trials. ${ }^{12}$

\section{Use of the Internet}

Recently, there have been studies exploring the provision of CBT via the Internet, and suggesting that this is a viable treatment alternative for PTSD. ${ }^{40}$ Online treatment of PTSD patients with therapist support by email only has been reported. An open trial involving a 10-week Internet-based therapist-assisted CBT for PTSD (PTSD Online) found that the participants showed clinically significant reductions in PTSD severity and symptomatology, moderate tolerance of the program content, and high therapeutic alliance ratings. ${ }^{1}$ In another analysis of PTSD Online participants, significant improvements in PTSD severity and PTSD symptomatology were observed at post-assessment and were maintained at three-month follow-up. At post-assessment, $69.2 \%$ of the sample showed clinically significant improvement versus $77 \%$ of the sample at follow-up assessment. Overall, treatment satisfaction was good (69\%), participant therapeutic alliance ratings were high $(87.5 \%)$, and the average total therapist time required was 194.5 minutes. ${ }^{113}$ The results of CBT administered for PTSD by video conference compared with the face-to-face method showed a significant decline in the frequency and severity of post-traumatic symptoms after both treatments and without significant differences. A clinical improvement in overall functioning was also observed. ${ }^{114}$

\section{CBT methods in children}

Trauma-focused CBT, an evidence-based practice for children, is being disseminated and implemented through a variety of strategies, including distance learning/Internet training, live training in addition to ongoing phone consultation, a learning collaborative model, and mixed models. It has been used to spread the trauma-focused CBT model among community clinicians treating traumatized children. Data from these dissemination/implementation models vary, but overall they support the effectiveness of both the 
trauma-focused CBT model in treating traumatized children and a variety of dissemination and implementation models. ${ }^{115}$ Short-term group CBT has been found to be a useful treatment approach with long-term benefit. Significant improvement was reported in children at 18-month follow-up, with treatment gains being maintained at four-year follow-up. ${ }^{79}$ It has been suggested that, where appropriate, families should be involved in the treatment of PTSD in children and young people. ${ }^{6}$ In adolescents with PTSD, CBT has been provided in school-based treatment programs using manualized CBT intervention delivered in a group format. It has been found that this method of delivering CBT for 10 weeks has the potential to help some children who experience PTSD symptoms and depression. ${ }^{116}$ Large-scale community projects to provide CBT for children and adolescents following major disasters have been attempted, eg, the Child and Adolescent Trauma Treatments and Services Consortium following the 9/11 World Trade Center disaster. Treatments were delivered in either school or clinic settings by clinicians in New York City. All participating clinicians were trained to use the CBT models and received case consultation for 18 months by expert clinician consultants and the treatment developers. ${ }^{117}$ This exercise can provide a model for implementing CBT in communities following massive disasters.

\section{Mechanisms of change}

The mechanisms behind the effectiveness of CBT for PTSD are still poorly understood. It is essential to discuss the current understanding of various mechanisms behind the effectiveness of CBT in PTSD. Both psychological and biological factors are discussed.

\section{Theoretical understanding}

Various cognitive distortions are seen in PTSD, depending on the traumatic experience and the nature of the psychological state of the person. Common cognitive distortions include perceiving the world as dangerous, seeing oneself as powerless or inadequate, or feeling guilty about outcomes that could not have been prevented. ${ }^{118}$ Many survivors feel guilty, thinking that they could have done more to limit the damage, or prevent injury or death in near and dear ones, and may have suicidal ideation. ${ }^{119,120} \mathrm{~A}$ study has also indicated that PTSD is associated with negative beliefs about self that may influence self-esteem and interpersonal relationships. ${ }^{121}$ PTSD often co-occurs with depression, and they may share common risk factors. One possible common cognitive risk factor is hopelessness. In a study of female survivors of interpersonal violence, relationships between hopelessness and symptoms of PTSD were due almost entirely to shared variance with depression. ${ }^{122}$

Cognitive therapy is based on an underlying theoretical rationale that an individual's affect and behavior are largely determined by the way he/she thinks and structures the world around him/her. ${ }^{123} \mathrm{CBT}$ addresses the twin issues of lack of control and the unpredictability inherent in traumatic situations. ${ }^{7}$ Victims generally begin to experience improvement in symptoms and behavior as they begin to think and act more realistically and adaptively with regard to their situational and psychological difficulties. In adults, children, and adolescents with PTSD, the effects of CBT have been observed to be partially mediated by changes in maladaptive cognitions, as predicted by cognitive models of PTSD. ${ }^{34}$ It has been proposed that successful processing of traumatic events involves emotional engagement with the trauma memory, organization of the trauma narrative, and correction of dysfunctional cognitions that often follow trauma. ${ }^{124}$ Imagery rescripting has long been part of CBT, especially for patients who struggle with distressing, intrusive imagery. Studies now explore a variety of imagery rescripting techniques in the treatment of PTSD. ${ }^{125}$ One study investigated trauma processing during and after CBT consisting of imaginal exposure combined with rescripting. The results suggested that imaginal reliving during CBT is not crucial for symptom reduction, but it may promote conceptual processing, which in itself predicts a better treatment outcome for PTSD. ${ }^{111}$

Prolonged exposure has been reported to be effective for improving post-traumatic stress symptoms in 60\%-65\% of trauma victims suffering from PTSD. However, a simple habituation model (on which prolonged exposure is based) is observed to be insufficient to address non-fear emotions (eg, guilt, shame, anger) in PTSD. In contrast, by adding an imagery-based, cognitive restructuring component (imagery rescripting and reprocessing therapy) to the treatment of patients of PTSD who have failed to improve with prolonged exposure alone, $78.3 \%$ of clients showed full recovery from their PTSD symptoms and no longer met criteria for PTSD after 1-3 sessions of imagery rescripting and reprocessing therapy. It suggests that individualized trauma assessments should be conducted for each patient to identify the predominant trauma-related emotions and cognitions which will help to find the best CBT "treatment fit" for the specific trauma characteristics of each patient. ${ }^{126}$

\section{Biological underpinnings}

It is interesting to note that CBT has been found to have an impact on the physiological parameters associated 
with PTSD, suggesting improvement. Many studies have explored these areas, and reported a greater decrease of heart rate reactivity ${ }^{20}$ and improvement of systolic blood pressure response to orthostasis after CBT in PTSD patients. ${ }^{28} \mathrm{CBT}$ also affects the startle response in PTSD. A significant reduction in electromyographic reactivity to all stimuli was observed in motor vehicle accident survivors who received active treatment, either CBT or supportive therapy, compared with wait-list controls. Based on this, startle responses have been suggested as a PTSD treatment outcome index. ${ }^{127}$ Neuropsychological functioning in individuals with PTSD and their response to CBT has been studied. A study reported that nonresponders to treatment had significantly poorer performance on measures of verbal memory compared with responders and also demonstrated narrative encoding deficits. Verbal memory deficits seem to diminish the effectiveness of CBT and should be considered in its implementation. ${ }^{128}$

In another study involving motor vehicle accident survivors, there was a greater reduction of right anterior activation of spontaneous electroencephalographic activity in the CBT group as compared with wait-list controls following treatment. Across both groups, PTSD symptom reduction was significantly and positively correlated with a decrease in right anterior activation to the trauma stimulus. ${ }^{19}$ One study examined functional magnetic resonance imaging responses of the brain pre-post CBT in individuals with PTSD. Poor improvement after treatment was associated with greater bilateral amygdala and ventral anterior cingulate activation in response to masked fearful faces. This excessive amygdala response to fear may reflect difficulty in managing anxiety reactions elicited during CBT, and this factor may limit optimal response to therapy. ${ }^{92}$

\section{Conclusion}

The current review suggests that CBT is an effective treatment for both acute and chronic PTSD, with both short-term and long-term benefit, following a range of traumatic experiences. It has been found to be at least as effective as various other psychological interventions. CBT has been used in children and adolescents suffering from PTSD, even in preschoolers, with positive outcomes. CBT has been culturally validated, and has been used successfully by community therapists following brief training, in individual and group settings. In addition to the traditional face-to-face and group settings, there has been increasingly effective use of the technique via the Internet. In spite of reports of efficacy in many studies, nonresponse to CBT for PTSD can be as high as $50 \%$. This is contributed to by various factors, including comorbidities and nature of the study population.
Current evidence suggests both a psychological and neurophysiological basis for the response to CBT. The preventive potential of CBT for PTSD has been recognized, when instituted early in at-risk populations. However the evidence for definitive recommendations is not satisfactory. There is a need for more studies in developing countries following disasters that affect huge populations. CBT for PTSD following massive disasters should be studied with high methodological rigor given its public health importance. The preventive potential of early CBT needs further confirmation, considering the enormous number of at-risk individuals.

\section{Acknowledgment}

The author thanks the Quality of Life Research and Development Foundation for its support in this research.

\section{Disclosure}

The author reports no conflicts of interest in this work.

\section{References}

1. Klein B, Mitchell J, Gilson K, et al. A therapist-assisted Internet-based CBT intervention for posttraumatic stress disorder: Preliminary results. Cogn Behav Ther. 2009;38(2):12-31.

2. Bisson JI. Post-traumatic stress disorder. Clin Evid (Online). 2007; pii: 1005 .

3. Kolassa IT, Ertl V, Eckart C, et al. Association study of trauma load and SLC6A4 promoter polymorphism in posttraumatic stress disorder: Evidence from survivors of the Rwandan genocide. J Clin Psychiatry. 2010;71(5):543-547.

4. American Psychiatric Association. Diagnostic and Statistical Manual of Mental Disorders. 3rd ed. Washington, DC: American Psychiatric Association; 1980.

5. Cahill SP, Foa EB, Hembree EA, Marshall RD, Nacash N. Dissemination of exposure therapy in the treatment of posttraumatic stress disorder. J Trauma Stress. 2006;19(5):597-610.

6. National Institute for Clinical Excellence. Post-traumatic stress disorder (PTSD): The management of PTSD in adults and children in primary and secondary care. In: NICE Clinical Guideline No. 26. London: National Institute for Clinical Excellence; 2005.

7. Garakani A, Hirschowitz J, Katz CL. General disaster psychiatry. Psychiatr Clin North Am. 2004;27(3):391-406.

8. Expert Consensus Panel. The expert consensus guideline series. Treatment of Posttraumatic stress disorder. The Expert Consensus Panels for PTSD. J Clin Psychiatry. 1999;60 Suppl 16:3-76.

9. Forbes D, Creamer M, Phelps A, et al. Australian guidelines for the treatment of adults with acute stress disorder and post-traumatic stress disorder. Aust N Z J Psychiatry. 2007;41(8):637-648.

10. Bisson JI, Tavakoly B, Witteveen AB, et al. TENTS guidelines: Development of post-disaster psychosocial care guidelines through a Delphi process. Br J Psychiatry. 2010;196(1):69-74.

11. Sijbrandij M, Olff M, Reitsma JB, Carlier IV, de Vries MH, Gersons BP. Treatment of acute posttraumatic stress disorder with brief cognitive behavioral therapy: A randomized controlled trial. Am J Psychiatry. 2007;164(1):82-90.

12. Cottraux J, Note I, Yao SN, et al. Randomized controlled comparison of cognitive behavior therapy with Rogerian supportive therapy in chronic post-traumatic stress disorder: A 2-year follow-up. Psychother Psychosom. 2008;77(2):101-110. 
13. Van Emmerik AA, Kamphuis JH, Emmelkamp PM. Treating acute stress disorder and posttraumatic stress disorder with cognitive behavioral therapy or structured writing therapy: A randomized controlled trial. Psychother Psychosom. 2008;77(2):93-100.

14. Hien DA, Cohen LR, Miele GM, Litt LC, Capstick C. Promising treatments for women with comorbid PTSD and substance use disorders. Am J Psychiatry. 2004;161(8):1426-1432.

15. Mueser KT, Rosenberg SD, Xie H, et al. A randomized controlled trial of cognitive-behavioral treatment for posttraumatic stress disorder in severe mental illness. J Consult Clin Psychol. 2008;76(2):259-271.

16. Shemesh E, Annunziato RA, Weatherley BD, et al. A randomized controlled trial of the safety and promise of cognitive-behavioral therapy using imaginal exposure in patients with posttraumatic stress disorder resulting from cardiovascular illness. J Clin Psychiatry 2011;72(2):168-174.

17. DuHamel KN, Mosher CE, Winkel G, et al. Randomized clinical trial of telephone-administered cognitive-behavioral therapy to reduce post-traumatic stress disorder and distress symptoms after hematopoietic stem-cell transplantation. J Clin Oncol. 2010;28(23): 3754-3761.

18. Zoellner T, Rabe S, Karl A, Maercker A. Post-traumatic growth as outcome of a cognitive-behavioural therapy trial for motor vehicle accident survivors with PTSD. Psychol Psychother. August 10, 2010. [Epub ahead of print].

19. Rabe S, Zoellner T, Beauducel A, Maercker A, Karl A. Changes in brain electrical activity after cognitive behavioral therapy for posttraumatic stress disorder in patients injured in motor vehicle accidents. Psychosom Med. 2008;70(1):13-19.

20. Rabe S, Dörfel D, Zöllner T, Maercker A, Karl A. Cardiovascular correlates of motor vehicle accident related posttraumatic stress disorder and its successful treatment. Appl Psychophysiol Biofeedback. 2006;31(4): 315-330.

21. Maercker A, Zöllner T, Menning H, Rabe S, Karl A. Dresden PTSD treatment study: Randomized controlled trial of motor vehicle accident survivors. BMC Psychiatry. 2006;6:29.

22. Blanchard EB, Hickling EJ, Malta LS, et al. One- and two-year prospective follow-up of cognitive behavior therapy or supportive psychotherapy. Behav Res Ther. 2004;42(7):745-759.

23. Beck JG, Coffey SF, Foy DW, Keane TM, Blanchard EB. Group cognitive behavior therapy for chronic posttraumatic stress disorder: An initial randomized pilot study. Behav Ther. 2009;40(1):82-92.

24. Blanchard EB, Hickling EJ, Devineni T, et al. A controlled evaluation of cognitive behavioural therapy for posttraumatic stress in motor vehicle accident survivors. Behav Res Ther. 2003;41(1):79-96.

25. Difede J, Malta LS, Best S, et al. A randomized controlled clinical treatment trial for World Trade Center attack-related PTSD in disaster workers. J Nerv Ment Dis. 2007;195(10):861-865.

26. Litz BT, Engel CC, Bryant RA, Papa A. A randomized, controlled proofof-concept trial of an Internet-based, therapist-assisted self-management treatment for posttraumatic stress disorder. Am J Psychiatry. 2007; 164(11):1676-1683.

27. Paunovic N, Ost LG. Cognitive-behavior therapy vs exposure therapy in the treatment of PTSD in refugees. Behav Res Ther. 2001;39(10): 1183-1197.

28. Hinton DE, Hofmann SG, Pollack MH, Otto MW. Mechanisms of efficacy of CBT for Cambodian refugees with PTSD: Improvement in emotion regulation and orthostatic blood pressure response. CNS Neurosci Ther. 2009;15(3):255-263.

29. Otto MW, Hinton D, Korbly NB, et al. Treatment of pharmacotherapy-refractory posttraumatic stress disorder among Cambodian refugees: A pilot study of combination treatment with cognitivebehavior therapy vs sertraline alone. Behav Res Ther. 2003;41(11): 1271-1276.

30. Hinton DE, Chhean D, Pich V, Safren SA, Hofmann SG, Pollack MH. A randomized controlled trial of cognitive-behavior therapy for Cambodian refugees with treatment-resistant PTSD and panic attacks: A cross-over design. J Trauma Stress. 2005;18(6):617-629.
31. Cohen JA, Mannarino AP, Iyengar S. Community treatment of posttraumatic stress disorder for children exposed to intimate partner violence: A randomized controlled trial. Arch Pediatr Adolesc Med. 2011;165(1): $16-21$

32. Foa EB, Zoellner LA, Feeny NC. An evaluation of three brief programs for facilitating recovery after assault. J Trauma Stress. 2006;19(1): 29-43.

33. McDonagh A, Friedman M, McHugo G, et al. Randomized trial of cognitive-behavioral therapy for chronic posttraumatic stress disorder in adult female survivors of childhood sexual abuse. J Consult Clin Psychol. 2005;73(3):515-524.

34. Smith P, Yule W, Perrin S, Tranah T, Dalgleish T, Clark DM. Cognitivebehavioral therapy for PTSD in children and adolescents: A preliminary randomized controlled trial. J Am Acad Child Adolesc Psychiatry. 2007; 46(8):1051-1061.

35. Cohen JA, Mannarino AP, Perel JM, Staron V. A pilot randomized controlled trial of combined trauma-focused CBT and sertraline for childhood PTSD symptoms. J Am Acad Child Adolesc Psychiatry. 2007;46(7):811-819.

36. Deblinger E, Mannarino AP, Cohen JA, Steer RA. A follow-up study of a multisite, randomized, controlled trial for children with sexual abuse-related PTSD symptoms. J Am Acad Child Adolesc Psychiatry. 2006;45(12):1474-1484.

37. Cohen JA, Mannarino AP, Knudsen K. Treating sexually abused children: 1 year follow-up of a randomized controlled trial. Child Abuse Negl. 2005;29(2):135-145.

38. Cohen JA, Deblinger E, Mannarino AP, Steer RA. A multisite, randomized controlled trial for children with sexual abuse-related PTSD symptoms. J Am Acad Child Adolesc Psychiatry. 2004;43(4): 393-402.

39. Hollifield M, Sinclair-Lian N, Warner TD, Hammerschlag R. Acupuncture for posttraumatic stress disorder: A randomized controlled pilot trial. J Nerv Ment Dis. 2007;195(6):504-513.

40. Knaevelsrud C, Maercker A. Internet-based treatment for PTSD reduces distress and facilitates the development of a strong therapeutic alliance: A randomized controlled clinical trial. BMC Psychiatry. 2007;7:13

41. Devilly GJ, Spence SH. The relative efficacy and treatment distress of EMDR and a cognitive-behavior trauma treatment protocol in the amelioration of posttraumatic stress disorder. J Anxiety Disord. 1999;13(1-2):131-157.

42. Levitt JT, Malta LS, Martin A, Davis L, Cloitre M. The flexible application of a manualized treatment for PTSD symptoms and functional impairment related to the 9/11 World Trade Center attack. Behav Res Ther. 2007;45(7):1419-1433.

43. Brewin CR, Fuchkan N, Huntley Z, et al. Outreach and screening following the 2005 London bombings: Usage and outcomes. Psychol Med. 2010;40(12):2049-2057.

44. Gillespie K, Duffy M, Hackmann A, Clark DM. Community based cognitive therapy in the treatment of posttraumatic stress disorder following the Omagh bomb. Behav Res Ther. 2002;40(4):345-357.

45. Miyahira SD, Folen RA, Hoffman HG, Garcia-Palacios A, Schaper KM. Effectiveness of brief VR treatment for PTSD in war-fighters: A case study. Stud Health Technol Inform. 2010;154:214-219.

46. Beidel DC, Frueh BC, Uhde TW, Wong N, Mentrikoski JM. Multicomponent behavioral treatment for chronic combat-related posttraumatic stress disorder: A randomized controlled trial. J Anxiety Disord. 2011;25(2):224-231.

47. Otis JD, Keane TM, Kerns RD, Monson C, Scioli E. The development of an integrated treatment for veterans with comorbid chronic pain and posttraumatic stress disorder. Pain Med. 2009;10(7):1300-1311.

48. Jaycox LH, Zoellner L, Foa EB. Cognitive-behavior therapy for PTSD in rape survivors. J Clin Psychol. 2002;58(8):891-906.

49. Nishith P, Duntley SP, Domitrovich PP, Uhles ML, Cook BJ, Stein PK Effect of cognitive behavioral therapy on heart rate variability during REM sleep in female rape victims with PTSD. J Trauma Stress. 2003;16(3):247-250. 
50. Foa EB, Hembree EA, Cahill SP, et al. Randomized trial of prolonged exposure for posttraumatic stress disorder with and without cognitive restructuring: Outcome at academic and community clinics. J Consult Clin Psychol. 2005;73(5):953-964.

51. Ponniah K, Hollon SD. Empirically supported psychological treatments for adult acute stress disorder and posttraumatic stress disorder: A review. Depress Anxiety. 2009;26(12):1086-1109.

52. Beck JG, Coffey SF. Group cognitive behavioral treatment for PTSD: Treatment of motor vehicle accident survivors. Cogn Behav Pract. 2005;12(3):267-277.

53. Taylor S, Fedoroff IC, Koch WJ, Thordarson DS, Fecteau G, Nicki RM. Posttraumatic stress disorder arising after road traffic collisions: Patterns of response to cognitive-behavior therapy. J Consult Clin Psychol. 2001; 69(3):541-551.

54. Palic S, Elklit A. Psychosocial treatment of posttraumatic stress disorder in adult refugees: A systematic review of prospective treatment outcome studies and a critique. J Affect Disord. August 12, 2010. [Epub ahead of print].

55. Hinton DE, Pham T, Tran M, Safren SA, Otto MW, Pollack MH. CBT for Vietnamese refugees with treatment-resistant PTSD and panic attacks: A pilot study. J Trauma Stress. 2004;17(5):429-433.

56. Başoğlu M, Ekblad S, Bäärnhielm S, Livanou M. Cognitive-behavioral treatment of tortured asylum seekers: A case study. J Anxiety Disord. 2004;18(3):357-369.

57. Zayfert C, DeViva JC. Residual insomnia following cognitive behavioral therapy for PTSD. J Trauma Stress. 2004;17(1):69-73.

58. DeViva JC, Zayfert C, Pigeon WR, Mellman TA. Treatment of residual insomnia after CBT for PTSD: Case studies. J Trauma Stress. 2005; 18(2):155-159.

59. Shemesh E, Koren-Michowitz M, Yehuda R, et al. Symptoms of posttraumatic stress disorder in patients who have had a myocardial infarction. Psychosomatics. 2006;47(3):231-239.

60. Lennmarken C, Sydsjo G. Psychological consequences of awareness and their treatment. Best Pract Res Clin Anaesthesiol. 2007;21(3):357-367.

61. Ayers S, McKenzie-McHarg K, Eagle A. Cognitive behaviour therapy for postnatal post-traumatic stress disorder: Case studies. J Psychosom Obstet Gynaecol. 2007;28(3):177-184.

62. Lapp LK, Agbokou C, Peretti CS, Ferreri F. Management of post traumatic stress disorder after childbirth: A review. J Psychosom Obstet Gynaecol. 2010;31(3):113-122.

63. Wagner AW. Cognitive-behavioral therapy for posttraumatic stress disorder: Applications to injured trauma survivors. Semin Clin Neuropsychiatry. 2003;8(3):175-187.

64. Williams WH, Evans JJ, Wilson BA. Neurorehabilitation for two cases of post-traumatic stress disorder following traumatic brain injury. Cogn Neuropsychiatry. 2003;8(1):1-18.

65. Eksi A, Braun KL. Over-time changes in PTSD and depression among children surviving the 1999 Istanbul earthquake. Eur Child Adolesc Psychiatry. 2009;18(6):384-391.

66. Shooshtary MH, Panaghi L, Moghadam JA. Outcome of cognitive behavioral therapy in adolescents after natural disaster. $J$ Adolesc Health. 2008;42(5):466-472.

67. Hamblen JL, Norris FH, Gibson L, Lee L. Training community therapists to deliver cognitive behavioral therapy in the aftermath of disaster. Int J Emerg Ment Health. 2010;12(1):33-40.

68. Hamblen JL, Norris FH, Pietruszkiewicz S, Gibson LE, Naturale A, Louis C. Cognitive behavioral therapy for postdisaster distress: A community based treatment program for survivors of Hurricane Katrina. Adm Policy Ment Health. 2009;36(3):206-214.

69. Harvey AG, Bryant RA, Tarrier N. Cognitive behaviour therapy for posttraumatic stress disorder. Clin Psychol Rev. 2003;23(3):501-522.

70. Bisson J, Andrew M. Psychological treatment of post-traumatic stress disorder (PTSD). Cochrane Database Syst Rev. 2007;(3):CD003388.

71. Kar N, Mohapatra PK, Nayak KC, Pattnaik P, Swain SP, Kar HC. Posttraumatic stress disorder in children and adolescents one year after a super-cyclone in Orissa, India: Exploring cross-cultural validity and vulnerability factors. BMC Psychiatry. 2007;7:8.
72. Kar N, Bastia BK. Post-traumatic stress disorder, depression and generalised anxiety disorder in adolescents after a natural disaster: A study of comorbidity. Clin Pract Epidemiol Ment Health. 2006;2:17.

73. Silva RR, Cloitre M, Davis L, et al. Early intervention with traumatized children. Psychiatr Q. 2003;74(4):333-347.

74. Donnelly CL, Amaya-Jackson L. Post-traumatic stress disorder in children and adolescents: Epidemiology, diagnosis and treatment options. Paediatr Drugs. 2002;4(3):159-170.

75. Scheeringa MS, Salloum A, Arnberger RA, Weems CF, Amaya-Jackson L, Cohen JA. Feasibility and effectiveness of cognitive-behavioral therapy for posttraumatic stress disorder in preschool children: Two case reports. J Trauma Stress. 2007;20(4):631-636.

76. Adler-Nevo G, Manassis K. Psychosocial treatment of pediatric posttraumatic stress disorder: The neglected field of single-incident trauma. Depress Anxiety. 2005;22(4):177-189.

77. March JS, Amaya-Jackson L, Murray MC, Schulte A. Cognitivebehavioral psychotherapy for children and adolescents with posttraumatic stress disorder after a single-incident stressor. J Am Acad Child Adolesc Psychiatry. 1998;37(6):585-593.

78. Kar N. Psychological impact of disasters on children: Review of assessment and interventions. World J Pediatr. 2009;5(1):5-11.

79. Giannopoulou I, Dikaiakou A, Yule W. Cognitive-behavioural group intervention for PTSD symptoms in children following the Athens 1999 earthquake: A pilot study. Clin Child Psychol Psychiatry. 2006;11(4): 543-553.

80. Cohen JA, Berliner L, Mannarino AP. Psychosocial and pharmacological interventions for child crime victims. J Trauma Stress. 2003;16(2): 175-186.

81. Ehntholt KA, Yule W. Practitioner review: Assessment and treatment of refugee children and adolescents who have experienced war-related trauma. J Child Psychol Psychiatry. 2006;47(12):1197-1210.

82. Kataoka SH, Stein BD, Jaycox LH, et al. A school-based mental health program for traumatized Latino immigrant children. J Am Acad Child Adolesc Psychiatry. 2003;42(3):311-318

83. Khamis V. Post-traumatic stress and psychiatric disorders in Palestinian adolescents following intifada-related injuries. Soc Sci Med. 2008;67(8): 1199-1207.

84. Cohen JA. Treating acute posttraumatic reactions in children and adolescents. Biol Psychiatry. 2003;53(9):827-833.

85. King NJ, Heyne D, Tonge BJ, et al. Sexually abused children suffering from post-traumatic stress disorder: Assessment and treatment strategies. Cogn Behav Ther. 2003;32(1):2-12.

86. McGovern MP, Lambert-Harris C, Acquilano S, Xie H, Alterman AI, Weiss RD. A cognitive behavioral therapy for co-occurring substance use and posttraumatic stress disorders. Addict Behav. 2009;34(10): 892-897.

87. Mendes DD, Mello MF, Ventura P, Passarela Cde M, Mari Jde J. A systematic review on the effectiveness of cognitive behavioral therapy for posttraumatic stress disorder. Int J Psychiatry Med. 2008;38(3): 241-259.

88. Bisson JI, Ehlers A, Matthews R, Pilling S, Richards D, Turner S. Psychological treatments for chronic post-traumatic stress disorder. Systematic review and meta-analysis. Br J Psychiatry. 2007;190: 97-104.

89. Seidler GH, Wagner FE. Comparing the efficacy of EMDR and trauma-focused cognitive-behavioral therapy in the treatment of PTSD: A meta-analytic study. Psychol Med. 2006;36(11):1515-1522.

90. Olff M, Langeland W, Witteveen A, Denys D. A psychobiological rationale for oxytocin in the treatment of posttraumatic stress disorder. CNS Spectr. 2010;15(8):522-530.

91. Schottenbauer MA, Glass CR, Arnkoff DB, Tendick V, Gray SH. Nonresponse and dropout rates in outcome studies on PTSD: Review and methodological considerations. Psychiatry. 2008;71(2):134-168.

92. Bryant RA, Felmingham K, Kemp A, et al. Amygdala and ventral anterior cingulate activation predicts treatment response to cognitive behaviour therapy for post-traumatic stress disorder. Psychol Med. 2008;38(4):555-561. 
93. Zayfert C, Deviva JC, Becker CB, Pike JL, Gillock KL, Hayes SA. Exposure utilization and completion of cognitive behavioral therapy for PTSD in a "real world" clinical practice. J Trauma Stress. 2005;18(6):637-645.

94. Bryant RA, Moulds ML, Nixon RD, Mastrodomenico J, Felmingham K, Hopwood S. Hypnotherapy and cognitive behaviour therapy of acute stress disorder: A 3-year follow-up. Behav Res Ther. 2006;44(9): 1331-1315.

95. Bryant RA, Moulds ML, Nixon RV. Cognitive behaviour therapy of acute stress disorder: A four-year follow-up. Behav Res Ther. 2003; 41(4):489-494.

96. Durham RC, Chambers JA, Power KG, et al. Long-term outcome of cognitive behaviour therapy clinical trials in central Scotland. Health Technol Assess. 2005;9(42):1-174.

97. Rose S, Bisson J, Churchill R, Wessely S. Psychological debriefing for preventing post traumatic stress disorder (PTSD). Cochrane Database Syst Rev. 2002;(2):CD000560.

98. Aulagnier M, Verger P, Rouillon F. [Efficiency of psychological debriefing in preventing post-traumatic stress disorders]. Rev Epidemiol Sante Publique. 2004;52(1):67-79. French.

99. Bryant RA, Harvey AG, Dang ST, Sackville T, Basten C. Treatment of acute stress disorder: A comparison of cognitive-behavioral therapy and supportive counseling. J Consult Clin Psychol. 1998;66(5): 862-866.

100. Ehlers A, Clark D. Early psychological interventions for adult survivors of trauma: A review. Biol Psychiatry. 2003;53(9):817-826.

101. Kornør H, Winje D, Ekeberg Ø, et al. Early trauma-focused cognitivebehavioural therapy to prevent chronic post-traumatic stress disorder and related symptoms: A systematic review and meta-analysis. $B M C$ Psychiatry. 2008;8:81.

102. Roberts NP, Kitchiner NJ, Kenardy J, Bisson JI. Systematic review and meta-analysis of multiple-session early interventions following traumatic events. Am J Psychiatry. 2009;166(3):293-301.

103. Whealin JM, Ruzek JI, Southwick S. Cognitive-behavioral theory and preparation for professionals at risk for trauma exposure. Trauma Violence Abuse. 2008;9(2):100-113.

104. Zatzick DF, Koepsell T, Rivara FP. Using target population specification, effect size, and reach to estimate and compare the population impact of two PTSD preventive interventions. Psychiatry. 2009;72(4): 346-359.

105. Roberts NP, Kitchiner NJ, Kenardy J, Bisson J. Multiple session early psychological interventions for the prevention of post-traumatic stress disorder. Cochrane Database Syst Rev. 2009 8;3:CD006869.

106. Hetrick SE, Purcell R, Garner B, Parslow R. Combined pharmacotherapy and psychological therapies for post traumatic stress disorder (PTSD). Cochrane Database Syst Rev. 2010;7:CD007316.

107. Garakani A, Mathew SJ, Charney DS. Neurobiology of anxiety disorders and implications for treatment. Mt Sinai J Med. 2006;73(7): 941-949.

108. Rodrigues H, Figueira I, Gonçalves R, Mendlowicz M, Macedo T, Ventura P. CBT for pharmacotherapy non-remitters - a systematic review of a next-step strategy. J Affect Disord. 2011;129(1-3):219-228.

109. Udomratn P. Mental health and the psychosocial consequences of natural disasters in Asia. Int Rev Psychiatry. 2008;20(5):441-444.

110. Kar N. Natural disasters in developing countries: Mental health issues. Indian J Med Sci. 2009;63(8):327-329.

Neuropsychiatric Disease and Treatment

\section{Publish your work in this journal}

Neuropsychiatric Disease and Treatment is an international, peerreviewed journal of clinical therapeutics and pharmacology focusing on concise rapid reporting of clinical or pre-clinical studies on a range of neuropsychiatric and neurological disorders. This journal is indexed on PubMed Central, the 'PsycINFO' database and CAS, and is the official
111. Kindt M, Buck N, Arntz A, Soeter M. Perceptual and conceptual processing as predictors of treatment outcome in PTSD. J Behav Ther Exp Psychiatry. 2007;38(4):491-506.

112. Ehlers A, Clark DM, Hackmann A, et al. Intensive cognitive therapy for PTSD: A feasibility study. Behav Cogn Psychother. 2010; 38(4):383-398

113. Klein B, Mitchell J, Abbott J, et al. A therapist-assisted cognitive behavior therapy internet intervention for posttraumatic stress disorder: Pre-, post- and 3-month follow-up results from an open trial. JAnxiety Disord. 2010;24(6):635-644.

114. Germain V, Marchand A, Bouchard S, Drouin MS, Guay S. Effectiveness of cognitive behavioural therapy administered by videoconference for posttraumatic stress disorder. Cogn Behav Ther. 2009;38(1):42-53.

115. Cohen J, Mannarino AP. Disseminating and implementing traumafocused CBT in community settings. Trauma Violence Abuse. 2008; 9(4):214-226.

116. Morsette A, Swaney G, Stolle D, Schuldberg D, van den Pol R, Young M. Cognitive behavioral intervention for trauma in schools (CBITS): School-based treatment on a rural American Indian reservation. J Behav Ther Exp Psychiatry. 2009;40(1):169-178.

117. CATS Consortium. Implementing CBT for traumatized children and adolescents after september 11: Lessons learned from the Child and Adolescent Trauma Treatments and Services (CATS) Project. $J$ Clin Child Adolesc Psychol. 2007;36(4):581-592.

118. Friedman MJ. Posttraumatic stress disorder among military returnees from Afghanistan and Iraq. Am J Psychiatry. 2006;163(4):586-593.

119. Kar N. Psychosocial issues following a natural disaster in a developing country: A qualitative longitudinal observational study. Int $J$ Disaster Med. 2006;4:169-176.

120. Kar N. Suicidality following a natural disaster. Am J Disaster Med. 2010;5(6):361-368.

121. Christensen PN, Cohan SL, Stein MB. The relationship between interpersonal perception and post-traumatic stress disorder-related functional impairment: A social relations model analysis. Cogn Behav Ther. 2004;33(3):151-160.

122. Scher CD, Resick PA. Hopelessness as a risk factor for post-traumatic stress disorder symptoms among interpersonal violence survivors. Cogn Behav Ther. 2005;34(2):99-107.

123. Kar N, Misra BN. Mental Health Care Following Disasters. Bhubaneswar: Quality of Life Research and Development Foundation; 2008.

124. Hembree EA, Foa EB. Posttraumatic stress disorder: Psychological factors and psychosocial interventions. J Clin Psychiatry. 2000;61 Suppl 7:33-39.

125. Holmes EA, Arntz A, Smucker MR. Imagery rescripting in cognitive behaviour therapy: Images, treatment techniques and outcomes. J Behav Ther Exp Psychiatry. 2007;38(4):297-305.

126. Grunert BK, Weis JM, Smucker MR, Christianson HF. Imagery rescripting and reprocessing therapy after failed prolonged exposure for post-traumatic stress disorder following industrial injury. $J$ Behav Ther Exp Psychiatry. 2007;38(4):317-328.

127. Karl A, Malta LS, Alexander J, Blanchard EB. Startle responses in motor vehicle accident survivors: A pilot study. Appl Psychophysiol Biofeedback. 2004;29(3):223-231.

128. Wild J, Gur RC. Verbal memory and treatment response in post-traumatic stress disorder. Br J Psychiatry. 2008;193(3):254-255.

\section{Dovepress}

journal of The International Neuropsychiatric Association (INA). The manuscript management system is completely online and includes a very quick and fair peer-review system, which is all easy to use. Visit http://www.dovepress.com/testimonials.php to read real quotes from published authors. 